\title{
Beberapa Sifat Integral Henstock Sekuensial
}

\author{
Malahayati \\ Program Studi Matematika Fakultas Sains dan Teknologi, UIN Sunan Kalijaga, Jl. Marsda Adisucipto \\ No. 1 Yogyakarta, Indonesia
}

Korespondensi; Email: malahayati_01@yahoo.co.id

\begin{abstract}
Abstrak
Perkembangan teori integral khususnya integral Henstock yang terbaru berhasil dikemukakan oleh Laramie Paxton, yaitu integral Henstock Sekuensial. Pendefinisian Integral Henstock Sekuensial hampir sama seperti mendefinisikan integral Henstock, bedanya pada integral Henstock Sekuensial partisinya melibatkan barisan fungsi positif yang disebut partisi tag $\delta_{\mathrm{n}}$-fine. Laramie membuktikan bahwa fungsi yang terintegral Henstock juga terintegral Henstock Sekuensial begitupun sebaliknya, sehingga sifat-sifat yang berlaku pada integral Henstock juga belaku pada integral Henstock Sekuensial. Di dalam tulisan ini dibuktikan beberapa sifat integral Henstock Sekuenisial dan teoremateorema dasar seperti yang berlaku pada integral Henstock.
\end{abstract}

Kata Kunci: Integral Henstock; Integral Henstock Sekuensial; partisi tag $\delta_{\mathrm{n}}$-fine

\begin{abstract}
The development of integral theories, in particular the latest Henstock integral, was succeeded by Laramie Paxton, the Sequential Henstock integral. The definition of a Sequential Henstock Integral is almost the same as defining the integral of Henstock, the difference in the Henstock integral Sequential partition involves a sequence of positive functions called the $\delta_{n}$-fine tag partition. Laramie proves that Henstock's integral function is also integral to Sequential Henstock as well as vice versa, so that the properties that apply to the integral Henstock also apply to the Sequential Henstock integral. In this paper some of the attributes of Henstock Sekuenisial integrals and basic theorems such as those that apply to the integral Henstock.
\end{abstract}

Keywords: Integral Henstock; Sequential Henstock Integral; $\delta_{\mathrm{n}}$-fine tag partition

\section{Pendahuluan}

Ilmu pengetahuan merupakan hal yang mengalami perkembangan secara terus-menerus. Diantaranya teori integral yaitu ilmu bidang matematika analisis yang terus mengalami perkembangan, dan memungkinkan untuk terus diteliti dan dikembangkan. Pada tahun 1854, teori integral dengan penggunaan partisi sebagai dasar pengembangannya telah disusun oleh Riemann. Teori Integral Riemann merupakan teori integral yang mudah dipelajari dan dimengerti dalam mempelajarinya. Namun demikian, seiring jalannya waktu teori Integral Riemann juga mengalami perkembangan. Ralph Henstock (1957) seorang ahli matematikawan, mencermati ada fungsi yang tidak terintegral Riemann. Sebagaimana diketahui pendefinisian integral yang dilakukan Riemann hanya membahas fungsi yang terbatas, namun demikian tidak semua fungsi yang terbatas terintegralkan secara Riemann, contoh fungsi yang tidak terintegral Riemann adalah fungsi Dirichlet. Dengan menggunakan partisi, Henstock menyusun teori integral baru yang dikenal dengan nama Integral Henstock.

Baru-baru ini, tepat di tahun 2016 perkembangan teori integral yang terbaru berhasil dikemukakan oleh Laramie Paxton, yaitu perkembangan dari integral Henstock menjadi integral Henstock Sekuensial melalui penggunaan urutan umum atau biasa disebut barisan, yaitu, integral Henstock didefinisikan melalui pendekatan barisan. Lebih lanjut, Laramie membuktikan bahwa fungsi yang terintegral Henstock juga terintegral Henstock Sekuensial begitupun sebaliknya, sehingga sifat-sifat yang berlaku pada integral Henstock juga belaku pada integral Henstock Sekuensial. Oleh karena itu, menarik untuk dipelajari sifat-sifat apa saja yang berlaku pada integral Henstock Sekuensial serta mengkaji lebih dalam bukti-bukti yang tidak diberikan oleh Laramie Paxton. 


\section{Landasan Teori}

Pada bagian ini, akan diberikan definisi partisi, yang telah dikenal ketika mendefinisikan integral Riemann maupun integral Henstock. Namun akan diberikan definisi non-overlapping terlebih dahulu.

Definisi 2.1. (Bartle, 2001:4) Dua interval terbuka pada $\mathbb{R}$ dikatakan tidak tumpang tindih (nonoverlapping) apabila irisan dari kedua interval tersebut kosong atau dua interval tertutup pada $\mathbb{R}$ dikatakan tidak tumpang tindih (non-overlapping) apabila irisan dari kedua interval tersebut paling banyak satu titik.

Berikut akan diberikan contoh agar lebih mudah dalam memahami definisi dua interval yang tidak tumpang tindih (non-overlapping).

Contoh 2.2. Diberikan masing-masing dua pasang interval pada $\mathbb{R}$ :

a. $A=[0,2]$ dan $B=[2,5]$

Dua interval tersebut dikatakan tidak tumpang tindih (non-overlapping), karena $A \cap B=\{2\}$.

b. $P=(2,4)$ dan $Q=(5,7)$

Interval $P$ dan $Q$ dikatakan tidak tumpang tindih (non-overlapping), karena $A \cap B=\emptyset$.

c. $R=[1,3]$ dan $S=[2,4]$

Dua interval tersebut dikatakan tumpang tindih (overlapping), karena

$R \cap S=[2,3]$.

Definisi 2.3. (Bartle, 2000:145) Partisi $P$ pada suatu interval $I=[a, b]$ adalah koleksi interval-interval tertutup yang non-overlapping sehingga $I=I_{1} \cup \ldots \cup I_{n}$. Ditulis $P=\left\{I_{1}, \ldots, I_{n}\right\}$ dengan $I_{i}=\left[x_{i-1}, x_{i}\right]$ dimana

$$
a=x_{0}<\cdots<x_{i-1}<x_{i}<\cdots<x_{n-1}<x_{n}=b
$$

Titik-titik $x_{i}(i=0, \ldots, n)$ disebut titik-titik partisi $P$. Jika titik $t_{i}$ dipilih dari setiap interval $I_{i}, \forall i=$ $1, \ldots, n$, maka $t_{i}$ disebut tag dan himpunan pasangannya disebut partisi tag pada I dapat ditulis

$$
P=\left\{\left(\left[x_{i-1}, x_{i}\right], t_{i}\right)\right\}_{i=1}^{k}
$$

Dengan $x_{i-1} \leq t_{i} \leq x_{i}$.

Berikut akan diberikan contoh partisi dan partisi tag agar lebih mudah dalam memahami definisi partisi di atas.

Contoh 2.4. Diberikan interval $A=[0,12]$

dibentuk $\quad P_{1}=\{[0,3],[3,6],[6,9],[9,12]\}$

$P_{2}=\{[0,2],[2,4],[4,6],[6,8],[8,10],[10,12]\}$

maka $P_{1}$ dan $P_{2}$ disebut partisi.

Dapat dipilih $t_{i}$ dari setiap $I_{i}$, sehingga dapat dibentuk partisi tag pada $A$ :

$$
\begin{gathered}
P_{1}=\{([0,3], 1),([3,6], 5),([6,9], 7),([9,12], 11)\} \\
P_{2}=\{([0,2], 1),([2,4], 3),([4,6], 5),([6,8], 7),([8,10], 9),([10,12], 11)\}
\end{gathered}
$$

Selanjutnya, akan diberikan definisi partisi $\delta$ - fine yang menjadi dasar terbentuknya integral Riemann.

Definisi 2.5. (Paxton, 2016:3) Diberikan $\delta>0$, partisi tag $P$ pada $I=[a, b]$ dikatakan $\delta$-fine apabila setiap subinterval $\left[x_{i-1}, x_{i}\right] \subset[a, b]$, memenuhi

$$
x_{i}-x_{i-1}<\delta, \forall i=1,2, \ldots, k \text {. }
$$


Berikut akan diberikan contoh partisi $\delta$-fineagar lebih mudah dalam memahami definisi partisi $\delta-$ fine.

Contoh 2.6. Diberikan $\delta=3$. Berdasarkan Contoh 2.4. dapat disimpulkan bahwa:

- $P_{1}$ bukan merupakan partisi $\delta-$ fine karena ada subinterval $[0,3] \subset A$ tetapi $3-0>\delta=3$

- $P_{2}$ merupakan partisi $\delta$ - fine.

Definisi integral Riemann, memotivasi Henstock memodifikasi partisi yang digunakan oleh Riemann sehingga terbentuk integral Henstock dengan definisi partisi $\delta(x)$-fine berikut.

Definisi 2.7. (Wells, 2011:10) Diberikan $I=[a, b]$ dan $\delta(x): I \rightarrow \mathbb{R}$ merupakan fungsi positif sehingga $\delta(x)>0, \forall x \in I$. Himpunan $P$ dikatakan partisi $\delta(x)$-fine pada I apabila memenuhi

$$
\left[x_{i-1}, x_{i}\right] \subseteq\left(t_{i}-\delta\left(t_{i}\right), t_{i}+\delta\left(t_{i}\right)\right)
$$

$\forall i=1, \ldots, n$, atau dengan kata lain, partisi tag $P=\left\{\left(\left[x_{i-1}, x_{i}\right], t_{i}\right)\right\}_{i=1}^{k}$ dikatakan $\delta(x)$-fine apabila setiap subinterval $\left[x_{i-1}, x_{i}\right]$ memenuhi:

$$
x_{i}-x_{i-1}<\delta\left(t_{i}\right), \forall i=1,2, \ldots, k,
$$

dengan $x_{i-1} \leq t_{i} \leq x_{i}$.

Berikut akan diberikan contoh partisi $\delta(x)$ - fine agar lebih mudah dalam memahami definisi partisi $\delta(x)-$ fine.

Contoh 2.8. Diberikan interval $I=[0,1]$ dan didefinisikan fungsi:

$$
\delta(x)=\left\{\begin{aligned}
1 / 4, & x=0 \\
2 x, & 0<x \leq 1
\end{aligned}\right.
$$

dapat dibentuk $P$ yang merupakan partisi $\delta(x)$ :

$$
P=\left\{\left(\left[0, \frac{1}{4}\right], \frac{1}{4}\right),\left(\left[\frac{1}{4}, \frac{2}{4}\right], \frac{1}{4}\right),\left(\left[\frac{2}{4}, \frac{3}{4}\right], \frac{2}{4}\right),\left(\left[\frac{3}{4}, 1\right], \frac{7}{8}\right)\right\} .
$$

Definisi 2.9. (Paxton, 2016: 3) Diberikan fungsi $\delta: I \rightarrow \mathbb{R}$ dengan $\delta(x)>0$, untuk setiap $x \in I$, yang kemudian $\delta(x)$ disebuat gauge pada I.

Definisi-definisi diatas sangat bermanfaat dalam pendefinisian integral Henstock sekuensial serta pembuktian beberapa sifatnya.

Lemma berikut ini akan digunakan dalam pembuktian teorema-teorema pada integral Henstock Sekuensial.

Lemma 2.10. (Wells, 2011:14) Diberikan fungsi positif $\delta(x)$ yang didefinisikan pada $[a, b]$, dan interval tag $(t,[a, b])$. Interval $(t,[a, b])$ merupakan partisi tag $\delta(x)$-fine pada $[a, b]$ jika dan hanya jika $\{(t,[a, t]),(t,[t, b])\}$ merupakan partisi tag $\delta(x)$ fine pada $[a, b]$. Selanjutnya,

$$
f(t)(b-a)=f(t)(t-a)+f(t)(b-t) .
$$




\section{Bukti:}

(Syarat perlu)

Diketahui bahwa $(t,[a, b])$ merupakan partisi tag $\delta(x)$ - fine pada $[a, b]$ dengan $[a, t] \subseteq[a, b]$ dan $[t, b] \subseteq[a, b]$ serta $[a, b] \subseteq(t-\delta(t), t+\delta(t))$. Akibatnya, $\{(t,[a, t]),(t,[t, b])\}$ merupakan partisi tag $\delta(x)$ - fine pada $[a, b]$.

(Syarat cukup)

Diketahui bahwa $\{(t,[a, t]),(t,[t, b])\}$ merupakan partisi tag $\delta(x)$ - fine pada $[a, b]$ berarti

$$
[a, t] \subseteq(t-\delta(t), t+\delta(t))
$$

Dan

$$
[t, b] \subseteq(t-\delta(t), t+\delta(t))
$$

Sehingga diperoleh

$$
[a, t] \cup[t, b]=[a, b]
$$

dan

$$
[a, b] \subseteq(t-\delta(t), t+\delta(t))
$$

Oleh karena itu, $(t,[a, b])$ merupakan partisi tag $\delta(x)$ - fine pada $[a, b]$.

Selanjutnya,

$$
f(t)(b-a)=f(t) b-f(t) a+f(t) t-f(t) t=f(t)(t-a)+f(t)(b-t) .
$$

Berikut ini diberikan definisi integral Henstock, dapat digunakan dalam memahami integral Henstock Sekuensial. Pendefinisian integral Henstock menggunakan partisi tag $\delta(x)$-fine.

Definisi 2.11. (Bartle, 2001:12) Fungsi $f: I=[a, b] \rightarrow \mathbb{R}$ dikatakan terintegral Henstock pada I apabila terdapat bilangan positif $A \in \mathbb{R}$ dan untuk setiap $\varepsilon>0$, terdapat $\delta(x)>0$ sehingga untuk setiap $P=\left\{\left(\left[x_{i-1}, x_{i}\right], t_{i}\right)\right\}_{i=1}^{k}$ yang merupakan partisi tag $\delta(x)$-fine pada l berlaku

$$
\left|\sum_{i=1}^{k} f\left(t_{i}\right)\left(x_{i}-x_{i-1}\right)-A\right|<\varepsilon,
$$

atau dapat ditulis

$$
|S(f, P)-A|<\varepsilon
$$

Bilangan A disebut nilai integral Henstock fungsi $f$ pada I ditulisA $=\int_{a}^{b} f$, kemudian fungsif terintegral Henstock pada I dapat ditulisf $\in \mathcal{R}^{*}(I)$. diatas.

Berikut diberikan contoh fungsi terintegral Henstock, agar lebih mudah dalam memahami definisi

Contoh 2.12. Diberikan fungsi Dirichlet, $\forall x \in[0,1]$ didefinisikan

$$
f(x)= \begin{cases}1, & \text { jika } x \in \mathbb{Q} \\ 0, & \text { jika } x \notin \mathbb{Q}\end{cases}
$$

Akan dibuktikan bahwa $f(x)$ terintegral Henstock pada $[0,1]$ dan $\int_{0}^{1} f(x)=0$ 


\section{Penjelasan:}

Ambil sebarang $\varepsilon>0$, didefinisikan $E=\left\{x_{i} \in \mathbb{Q}, x_{i} \in[0,1]\right\}, \quad i=1,2,3, \ldots, n$, selanjutnya didefinisikan fungsi $\delta(x)$ pada $[0,1]$ dengan

$$
\delta\left(x_{i}\right)=\left\{\begin{array}{l}
\varepsilon / 2^{i+1}, \text { jika } x_{i} \in E \\
0, \quad \text { jika } x_{i} \notin E .
\end{array}\right.
$$

Untuk sebarang partisi $\delta(x)$ - fine pada $[0,1]$ berlaku

$$
\begin{aligned}
\left|\sum_{i=1}^{k} f\left(t_{i}\right)\left(x_{i}-x_{i-1}\right)-0\right| & =\left|\sum_{i=1}^{k} f\left(t_{i}\right)\left(x_{i}-x_{i-1}\right)\right| \\
& =\left|\sum_{x_{i} \in E}^{k} f\left(t_{i}\right)\left(x_{i}-x_{i-1}\right)+\sum_{x_{i} \notin E}^{k} f\left(t_{i}\right)\left(x_{i}-x_{i-1}\right)\right| \\
& \leq\left|\sum_{x_{i} \in E}^{k} f\left(t_{i}\right)\left(x_{i}-x_{i-1}\right)\right|+\left|\sum_{x_{i} \notin E}^{k} f\left(t_{i}\right)\left(x_{i}-x_{i-1}\right)\right| \\
& =\left|\sum_{x_{i} \in E}^{k} 1\left(x_{i}-x_{i-1}\right)\right|+\left|\sum_{x_{i} \notin E}^{k} 0\left(x_{i}-x_{i-1}\right)\right| \\
& =\left|\sum_{x_{i} \in E}^{k}\left(x_{i}-x_{i-1}\right)\right|+0 \\
& =\left|\sum_{x_{i} \in E}^{k}\left(x_{i}-x_{i-1}\right)\right| \\
& <\sum_{x_{i} \in E}^{k} \delta\left(x_{i}\right)<\sum_{x_{i} \in E}^{k} \varepsilon / 2^{i+1} \\
& =\varepsilon \sum_{x_{i} \in E}^{k} 1 / 2^{i+1}=\frac{1}{2} \varepsilon \sum_{x_{i} \in E}^{k} 1 / 2^{i} \\
& \frac{1}{2} \varepsilon .1=\frac{1}{2} \varepsilon<\varepsilon .
\end{aligned}
$$

Dengan kata lain, terbukti bahwa $f(x)$ terintegral Henstock pada $[0,1]$ dan $\int_{0}^{1} f(x)=0$.

\section{Hasil dan Pembahasan}

Berikut diberikan definisi integral Henstock Sekuensial, agar mudah dalam memahaminya dapat dilihat kembali definisi tentang partisi yang telah diberikan sebelumnya.

Definisi 3.1 (Paxton, 2016:9) Fungsi $f: I=[a, b] \rightarrow \mathbb{R}$ dikatakan terintegral Henstock Sekuensial pada I apabila terdapat bilangan positif $A$ dan suatu barisan fungsi positif $\left\{\delta_{n}(x)\right\}_{n=1}^{\infty}$ sehingga untuk setiap $P_{n}$ yang merupakan partisi tag $\delta_{n}(x)$-fine, berlaku 


$$
\left|\sum_{i=1}^{k} f\left(t_{i}\right)_{n}\left(x_{i}-x_{i-1}\right)_{n}-A\right|<\varepsilon
$$

atau dapat ditulis

$$
\left|S\left(f, P_{n}\right)-A\right|<\varepsilon
$$

Bilangan A disebut nilai integral Henstock Sekuensial fungsi $f$ pada I dengan $A=\int_{a}^{b} f$, kemudian fungsi $f$ terintegral Henstock Sekuensial pada I, dapat ditulis: $f \in H^{*}(I)$.

Berikut akan diberikan contoh fungsi terintegral Henstock Sekuensial, agar dapat memberi gambaran tentang definisi integral Henstock Sekuensial.

Contoh 3.2. (Paxton, 2016:9) Diberikan fungsi Dirichlet, $\forall x \in[0,1]$ didefinisikan

$$
f(x)= \begin{cases}1, & x \in \mathbb{Q} \\ 0, & x \notin \mathbb{Q}\end{cases}
$$

Akan dibuktikan bahwa fungsi $f$ terintegral Henstock Sekuensial pada $[0,1]$ dan $\int_{0}^{1} f(x)=0$.

\section{Penjelasan:}

Didefinisikan keluarga bilangan rasional $\left\{q_{m}\right\}$ untuk setiap $m \in \mathbb{N}$.

Ambil sebarang bilangan $\varepsilon>0$, dan $\left\{\delta_{n}(x)\right\}_{n=1}^{\infty}$ merupakan fungsi gauge yang turun pada $[0,1]$ artinya $\delta_{n+1}(x)<\delta_{n}(x), \forall x \in I$ akibatnya, untuk setiap $t_{i} \in I_{i}$, dengan $I_{i}=\left[x_{i-1}-x_{i}\right], i=$ $1,2,3, \ldots, k$, dan $P_{n}=\left\{\left(\left[x_{i-1}-x_{i}\right], t_{i}\right)\right\}_{i=1}^{k}$ yang merupakan partisi $\delta_{n}(x)-$ fine juga turun, didefinisikan $I_{i}$

$$
I_{i} \subseteq\left[t_{i}-\frac{1}{2} \delta_{n}\left(t_{i}\right), t_{i}+\frac{1}{2} \delta_{n}\left(t_{i}\right)\right], \forall i=1,2,3, \ldots, k
$$

Jika $t$ merupakan titik tag, maka kita dapat memilih $N$ yang cukup besar dari barisan fungsi gauge tadi, dan didefinisikan:

$$
\delta_{N}(t)= \begin{cases}\frac{\varepsilon}{2^{m}}, & \text { jika } t=q_{m} \\ x, & \text { jika } t \notin \mathbb{Q} .\end{cases}
$$

Diberikan $P_{n}$ merupakan partisi $\delta_{n}(x)$ - fine pada [0,1] untuk setiap $n \geq N$. Jika $t_{i} \in I_{i}$ dan $t_{i} \notin$ $\mathbb{Q}$, maka $f\left(t_{i}\right)=0$, akibatnya jumlahan Riemannya bernilai 0. Jika $t_{i} \in I_{i}$ dan $t_{i} \in \mathbb{Q}$, maka $f\left(t_{i}\right)=$ 1, perhatikan dua kondisi berikut terlebih dahulu:

1. Jika $q_{m}$ merupakan tag pada interval $I_{i}$, maka:

$$
\begin{aligned}
& I_{i} \subseteq\left[q_{m}\right.\left.-\frac{1}{2} \delta_{n}\left(q_{m}\right), q_{m}+\frac{1}{2} \delta_{n}\left(q_{m}\right)\right] \\
& \text { sehingga }\left(x_{i}-x_{i-1}\right) \leq \delta_{n}\left(q_{m}\right) \leq \frac{\varepsilon}{2^{m}}=\delta_{N}(t) .
\end{aligned}
$$

2. Jika $q_{m}$ merupakan tag pada dua interval $I_{i}$ yang berurutan, maka:

karena

$$
\left(x_{i}-x_{i-1}\right)+\left(x_{i+1}-x_{i}\right) \leq \frac{\varepsilon}{2^{m}},
$$

$$
I_{i} \subseteq\left[q_{m}-\frac{1}{2} \delta_{n}\left(q_{m}\right), q_{m}\right] \Rightarrow x_{i}-x_{i-1} \leq \frac{1}{2} \delta_{n}\left(q_{m}\right),
$$


dan

maka,

$$
I_{i} \subseteq\left[q_{m}, q_{m}+\frac{1}{2} \delta_{n}\left(q_{m}\right),\right] \Rightarrow x_{i}-x_{i-1} \leq \frac{1}{2} \delta_{n}\left(q_{m}\right)
$$

sehingga,

$$
f\left(t_{i}\right)\left(x_{i}-x_{i-1}\right) \leq \frac{\varepsilon}{2^{m}}
$$

$$
\begin{aligned}
\left|S\left(f, P_{n}\right)-0\right| & =\left|\sum_{i=1}^{\infty} f\left(t_{i}\right)\left(x_{i}-x_{i-1}\right)-0\right| \\
& =\left|\sum_{i=1}^{\infty} f\left(t_{i}\right)\left(x_{i}-x_{i-1}\right)\right| \\
& \leq \sum_{i=1}^{\infty} \frac{\varepsilon}{2^{m}} \\
& =\varepsilon \sum_{i=1}^{\infty} \frac{1}{2^{m}}=\varepsilon \cdot 1=\varepsilon .
\end{aligned}
$$

Dengan kata lain, terbukti bahwa $f(x)$ terintegral Henstock Sekuensial pada $[0,1]$ dan $\int_{0}^{1} f(x)=0$. Berikut akan ditunjukan bahwa integral Henstock ekuivalen dengan integral Henstock Sekuensial.

Teorema 3.3. (Paxton, 2016:11) Fungsi $f:[a, b] \rightarrow \mathbb{R}$ terintegral Henstock pada $[a, b]$ jika dan hanya jika fungsi $f$ terintegral Henstock Sekuensial pada $[a, b]$.

\section{Bukti:}

Akan dibuktikan bahwa $f \in \mathcal{R}^{*}(I)$ jika dan hanya jika $f \in H^{*}(I)$. Asumsikan bahwa $\left\{\delta_{n}(x)\right\}_{n=1}^{\infty}$ adalah barisan fungsi gauge yang turun, sehingga berlaku

(Syarat perlu)

$$
\delta_{n+1}(x)<\delta_{n}(x), \forall x \in I
$$

Diketahui $f: I \rightarrow \mathbb{R}$ merupakan fungsi yang terintegral Henstock, artinya untuk setiap $\varepsilon>0$, terdapat $\delta(x)>0$ sehingga untuk setiap $P$ yang merupakan partisi $\delta(x)-f i n e$, berlaku

$$
|S(f, P)-A|<\varepsilon
$$

Untuk setiap $=1,2,3 \ldots$, diberikan $\varepsilon_{n}$ merupakan bilangan rasional $\varepsilon$ sehingga $0<\varepsilon<1$. Karena fungsi $f$ terintegral Henstock, maka terdapat $\delta_{n}(x)$ untuk setiap $\varepsilon_{n}$ yang memenuhi

$$
|S(f, P)-A|<\varepsilon .
$$

Jika $\mathbb{Q}$ adalah himpunan bilangan rasional yang terhitung, maka $\left\{\delta_{N}(x)\right\}_{n=1}^{\infty}$ adalah barisan. Untuk setiap $\varepsilon>0$, terdapat $\delta_{N}(x) \in\left\{\delta_{n}(x)\right\}_{n=1}^{\infty}$ sehingga untuk setiap $n \geq N$ dan $P_{n}$ yang merupakan barisan partisi $\delta_{n}(x)$ - fine pada $I$, berlaku

$$
\left|S\left(f, P_{n}\right)-A\right|<\varepsilon
$$

Jadi, dengan kata lain terbukti bahwa $f \in H^{*}(I)$. 
(Syarat cukup)

Diketahui $f: I \rightarrow \mathbb{R}$ merupakan fungsi yang terintegral Henstock Sekuensial, artinya, untuk setiap $\varepsilon>$ 0 terdapat barisan fungsi gauge $\left\{\delta_{n}(x)\right\}_{n=1}^{\infty}$ sehingga untuk setiap $P_{n}$ yang merupakan barisan partisi $\delta_{n}(x)$ - fine pada $I$, berlaku

$$
\left|S\left(f, P_{n}\right)-A\right|<\frac{1}{n}
$$

Diberikan $\lambda>0$, dipilih $\delta_{N}(x) \in\left\{\delta_{n}(x)\right\}_{n=1}^{\infty}$ sehingga untuk setiap $\delta(x)>0$, berlaku

$$
\left|\delta(x)-\delta_{N}(x)\right|<\lambda \forall x \in I
$$

Jika diberikan $\lambda \rightarrow 0$, maka $\delta_{N}(x)$ menjamin bahwa $P_{N}$ merupakan partisi $\delta_{n}(x)-f$ inedan juga merupakan partisi $\delta(x)$ - fine, sehingga untuk $P$ yang merupakan partisi $\delta(x)$ - fine, kita dapat membentuk jumlahan Riemann untuk $P \& P_{N}$ secara acak, sehingga

$$
\left|S(f, P)-S\left(f, P_{N}\right)\right|<\frac{\varepsilon}{2} .
$$

Selanjutnya, untuk setiap $\varepsilon>0$, terdapat $\delta(x)$ sehingga dapat ditemukan $\delta_{N}(x)$ yang memenuhi

$$
\left|\delta(x)-\delta_{N}(x)\right|<\lambda \forall x \in I,
$$

dan barisan $\left\{\delta_{n}(x)\right\}_{n=1}^{\infty}$ merupakan barisan turun dimana $n \geq N^{*}, \forall N^{*} \in \mathbb{N}$ sehingga $\frac{1}{N^{*}}<\frac{\varepsilon}{2}$. untuk setiap $P$ yang merupakan partisi $\delta(x)-$ fine berlaku

$$
\begin{aligned}
|S(f, P)-A| & =\left|S(f, P)-S\left(f, P_{N^{*}}\right)+S\left(f, P_{N^{*}}\right)-A\right| \\
& \leq\left|S(f, P)-S\left(f, P_{N^{*}}\right)\right|+\left|S\left(f, P_{N^{*}}\right)-A\right| \\
& <\frac{\varepsilon}{2}+\frac{1}{N^{*}}<\frac{\varepsilon}{2}+\frac{\varepsilon}{2}=\varepsilon .
\end{aligned}
$$

Teorema diatas secara tidak langsung mengatakan bahwa semua sifat-sifat dan teorema yang berlaku pada integral Henstock berlaku pula di integral Henstock Sekuensial. Berikut akan dibuktikan beberapa sifat yang telah berlaku di integral Henstock berlaku pula di integral Henstock Sekuensial. Diantaranya, apabila diberikan fungsi non negative maka nilai integral Henstock Sekuensial dari fungsi tersebut juga bernilai non negative. Selain itu pula nilai integral Henstock Sekuensial dari perkalian scalar dan suatu fungsi sama dengan scalar tersebut dikalikan dengan nilai dari integral Henstock sekuensial fungsi tersebut.

Teorema 3.4. (Paxton, 2016:15) Diberikan $f, g: I \rightarrow \mathbb{R}$ merupakan fungsi-fungsi yang terintegral Henstock Sekuensial pada $I=[a, b] \subset \mathbb{R}$, dan $c \in \mathbb{R}$.

i) Jika $f \geq 0$ pada I maka $\int_{I} f \geq 0$.

ii) cf terintegral Henstock Sekuensial pada I dan $\int_{I} c f=c \int_{I} f$.

iii) Jika $f+g$ terintegral Henstock Sekuensial pada I maka $\int_{I}(f+g)=\int_{I} f+\int_{I} g$.

iv) Jika $f(x) \leq g(x), \forall x \in I$, maka $\int_{I} f \leq \int_{I} g$. 


\section{Bukti:}

i) Diberikan $f \geq 0$ dan $f \in H^{*}(I)$, maka untuk setiap $\varepsilon>0$, terdapat $\delta_{N}(x) \in\left\{\delta_{n}(x)\right\}_{n=1}^{\infty}$ sehingga untuk setiap $n \geq N$ dan $P_{n}$ yang merupakan partisi $\delta_{n}(x)-f i n e$, berlaku

Artinya,

$$
\left|S\left(f, P_{n}\right)-\int_{I} f\right| \leq \varepsilon
$$

sehingga,

$$
\left|\sum_{i=1}^{k} f\left(t_{i}\right)\left(x_{i}-x_{i-1}\right)-\int_{I} f\right| \leq \varepsilon
$$

$$
\begin{array}{r}
-\varepsilon \leq \sum_{i=1}^{k} f\left(t_{i}\right)\left(x_{i}-x_{i-1}\right)-\int_{I} f \leq \varepsilon \\
\int_{I} f-\varepsilon \leq \sum_{i=1}^{k} f\left(t_{i}\right)\left(x_{i}-x_{i-1}\right) \leq \varepsilon+\int_{I} f,
\end{array}
$$

dengan $f\left(t_{i}\right) \geq 0$, untuk setiap $t_{i} \in P_{n}$ dan $\left(x_{i}-x_{i-1}\right) \geq 0$, maka diperoleh

$$
0 \leq \sum_{i=1}^{k} f\left(t_{i}\right)\left(x_{i}-x_{i-1}\right)=S\left(f, P_{n}\right)
$$

sehingga jika dikombinasikan dengan (3.2) menjadi

$$
0 \leq S\left(f, P_{n}\right) \leq \int_{I} f+\varepsilon \quad \forall n \geq N
$$

Jadi, dapat disimpulkan bahwa untuk setiap $\varepsilon>0$ berlaku $\int_{I} f \geq 0$.

ii) Diberikan $f \in H^{*}(I)$ artinya untuk setiap $\varepsilon>0$, terdapat $\delta_{N}(x) \in\left\{\delta_{n}(x)\right\}_{n=1}^{\infty}$ sehingga untuk setiap $n \geq N$ dan $P_{n}$ yang merupakan partisi $\delta_{n}(x)-f$ ine berlaku

$$
\left|S\left(f, P_{n}\right)-\int_{I} f\right| \leq \frac{\varepsilon}{|c|}
$$

Sehingga untuk setiap $n \geq N$ berlaku

$$
\begin{aligned}
\left|S\left(c f, P_{n}\right)-c \int_{I} f\right| & =\left|\sum_{i=1}^{k} c f\left(t_{i}\right)\left(x_{i}-x_{i-1}\right)-c \int_{I} f\right| \\
& =\left|c\left(\sum_{i=1}^{k} f\left(t_{i}\right)\left(x_{i}-x_{i-1}\right)-\int_{I} f\right)\right| \\
& =|c|\left|\sum_{i=1}^{k} f\left(t_{i}\right)\left(x_{i}-x_{i-1}\right)-\int_{I} f\right| \\
& =|c|\left|S\left(f, P_{n}\right)-\int_{I} f\right|
\end{aligned}
$$




$$
<|c| \frac{\varepsilon}{|c|}=\varepsilon
$$

sehingga $c f \in H^{*}(I)$ dan $\int_{I} c f=c \int_{I} f$.

iii) Ambil sebarang $\varepsilon>0$, karena $f \in H^{*}(I)$ maka terdapat $\delta_{M}(x) \in\left\{\delta_{m}(x)\right\}_{m=1}^{\infty}$ sehingga untuk setiap $m \geq M \in \mathbb{N}$ dan $P_{m}$ yang merupakan partisi $\delta_{m}(x)-$ fine, berlaku:

$$
\left|S\left(f, P_{m}\right)-\int_{I} f\right|<\frac{\varepsilon}{2},
$$

dan karena $g \in H^{*}(I)$, maka terdapat $\delta_{K}(x) \in\left\{\delta_{k}(x)\right\}_{k=1}^{\infty}$ sehingga untuk setiap $k \geq M \in \mathbb{N}$ dan $P_{k}$ yang merupakan partisi $\delta_{k}(x)-$ fine, berlaku:

$$
\left|S\left(g, P_{k}\right)-\int_{I} f\right|<\frac{\varepsilon}{2} .
$$

Selanjutnya, untuk setiap $\delta_{m}(x) \in\left\{\delta_{m}(x)\right\}_{m=1}^{\infty}$ dan $\delta_{k}(x) \in\left\{\delta_{k}(x)\right\}_{k=1}^{\infty}$, dipilih $\delta_{n}(x)=$ $\min \left\{\delta_{m}(x), \delta_{k}(x)\right\}$ dengan $n, m, k=1,2,3 \ldots \forall x \in I$. Jelas, $\delta_{n}(x)$ merupakan barisan fungsi gauge pada $I$. Jika $P_{n}$ merupakan partisi $\delta_{n}(x)$ - fine, maka $P_{n}$ merupakan partisi $\delta_{m}(x)$ - fine dan $P_{n}$ juga merupakan partisi $\delta_{k}(x)-$ fine.

Perhatikan bahwa untuk setiap $\varepsilon>0$, terdapat $\delta_{N}(x) \in\left\{\delta_{n}(x)\right\}_{n=1}^{\infty}$ sehingga untuk setiap $n \geq N$ dan $P_{n}$ yang merupakan partisi $\delta_{n}(x)-$ fine $P_{n}$, berlaku

$$
\begin{aligned}
& \left|S\left(f+g, P_{n}\right)-\left(\int_{I} f \int_{I} g\right)\right| \\
& =\left|\sum_{i=1}^{k}(f+g)\left(t_{i}\right)\left(x_{i}-x_{i-1}\right)-\left(\int_{I} f \int_{I} g\right)\right| \\
& =\left|\sum_{i=1}^{k} f\left(t_{i}\right)\left(x_{i}-x_{i-1}\right)-\int_{I} f+\sum_{i=1}^{k} g\left(t_{i}\right)\left(x_{i}-x_{i-1}\right)-\int_{I} g\right| \\
& \leq\left|\sum_{i=1}^{k} f\left(t_{i}\right)\left(x_{i}-x_{i-1}\right)-\int_{I} f\right|+\left|\sum_{i=1}^{k} g\left(t_{i}\right)\left(x_{i}-x_{i-1}\right)-\int_{I} g\right| \\
& <\frac{\varepsilon}{2}+\frac{\varepsilon}{2}=\varepsilon,
\end{aligned}
$$

sehingga, $f+g \in H^{*}(I)$ dan $\int_{I} f+g=\int_{I} f+\int_{I} g$.

iv) Diketahui $f, g \in H^{*}(I)$ dan $f(x) \leq g(x) \forall x \in I$. Diberikan $h=g-f \geq 0$ berdasarkan Teorema 3.3. bagian iii) maka berlaku

$$
h=g-f \in H^{*}(I)
$$

dan

$$
\int_{I}(g-f)=\int_{I} g+\int_{I}-f=\int_{I} g-\int_{I} f
$$


Selanjutnya, berdasarkan Teorema 3.3. bagian i), $\int_{I} h \geq 0$, sehingga

artinya,

$$
0 \leq \int_{I} h=\int_{I}(g-f)=\int_{I} g-\int_{I} f
$$

sehingga,

$$
0 \leq \int_{I} g-\int_{I} f
$$

$$
\int_{I} f \leq \int_{I} g
$$

Berikut akan diberikan sifat penambahan interval yang menyatakan bahwa Apabila suatu fungsi terintegral Henstock Sekuensial pada dua subinterval tertutup yang dimuat oleh suatu interval tertutup, maka fungsi tersebut juga terintegral Henstock Sekuensial pada interval tertutup tersebut, dan nilai integral dari fungsi yang terintegral Henstock Sekuensial pada interval tertutup tersebut merupakan penjumlahan dari nilai integral fungsi yang terintegral Henstock Sekuensial pada dua subinterval tersebut.

Teorema 3.5. (Paxton, 2016:18) Diberikan fungsi $f:[a, b] \rightarrow \mathbb{R}$ dan $c \in(a, b)$. Jika fungsi $f$ merupakan fungsi yang terintegral Henstock Sekuensial pada $[a, c]$ dan $[c, b]$, maka fungsi $f$ terintegral Henstock Sekuensial pada $[a, b]$ dan

$$
\int_{a}^{b} f=\int_{a}^{c} f+\int_{c}^{b} f .
$$

\section{Bukti:}

Ambil sebarang $\varepsilon>0$, karena $f \in H^{*}([a, c])$ maka terdapat $\delta_{M}(x) \in\left\{\delta_{m}(x)\right\}_{m=1}^{\infty}$ sehingga untuk setiap $m \geq M \in \mathbb{N}$ dan $P_{m}$ yang merupakan partisi $\delta_{m}(x)-$ fine, berlaku

$$
\left|S\left(f, P_{m}\right)-\int_{a}^{c} f\right|<\frac{\varepsilon}{2},
$$

dan juga karena $f \in H^{*}([c, b])$, maka terdapat $\delta_{K}(x) \in\left\{\delta_{k}(x)\right\}_{k=1}^{\infty}$ sehingga untuk setiap $k \geq K \in \mathbb{N}$ dan $P_{k}$ yang merupakan partisi $\delta_{k}(x)-$ fine, berlaku

$$
\left|S\left(f, P_{k}\right)-\int_{c}^{b} f\right|<\frac{\varepsilon}{2} .
$$

Didefinisikan gauge $\delta_{N}(x) \in\left\{\delta_{n}(x)\right\}_{n=1}^{\infty}$ sehingga untuk setiap $n \geq N \in \mathbb{N}$ dan $P_{n}$ yang merupakan partisi $\delta_{n}(x)$ - fine, setiap partisi $P_{n}$ dapat dipecahkan menjadi:

$$
\delta_{N}(t)=\left\{\begin{array}{ll}
\min \left\{\delta_{m}(t), \frac{1}{2}(c-t)\right\}, & t \in[a, c) \\
\min \left\{\delta_{m}(c), \delta_{k}(c)\right\}, & t=c \\
\min \left\{\delta_{k}(t), \frac{1}{2}(t-c)\right\}, & t \in(c, b]
\end{array} \quad \text { untuk } m \geq M \text { dan } k \geq K .\right.
$$


Diberikan $P_{n}$ merupakan partisi $\delta_{n}(x)$-fine, untuk setiap $n \geq N$, karena $P_{m}$ merupakan barisan partisi pada $[a, c]$ yang terdiri atas $P_{n} \cap[a, c]$, dan $P_{k}$ merupakan barisan partisi pada $[c, b]$ yang terdiri atas $P_{n} \cap[c, b]$ dengan $n, m, k=1,2,3 \ldots$ maka diperoleh

$$
S\left(f, P_{n}\right)=S\left(f, P_{m}\right)+S\left(f, P_{k}\right) .
$$

Untuk setiap $\varepsilon>0$, terdapat $\delta_{N}(x) \in\left\{\delta_{n}(x)\right\}_{n=1}^{\infty}$ sehingga untuk setiap $n \geq N$ berlaku

$$
\begin{aligned}
\left|S\left(f, P_{n}\right)-\left(\int_{a}^{c} f+\int_{c}^{b} f\right)\right| & =\left|\sum_{i=1}^{j} f\left(t_{i}\right)\left(x_{i}-x_{i-1}\right)_{n}-\left(\int_{a}^{c} f+\int_{c}^{b} f\right)\right| \\
& =\left|\sum_{i=1}^{p} f\left(t_{i}\right)\left(x_{i}-x_{i-1}\right)_{m} \sum_{i=p}^{j} f\left(t_{i}\right)\left(x_{i}-x_{i-1}\right)_{k}-\left(\int_{a}^{c} f+\int_{c}^{b} f\right)\right| \\
& =\left|S\left(f, P_{m}\right)-\int_{a}^{c} f+S\left(f, P_{k}\right)-\int_{c}^{b} f\right| \\
& \leq\left|S\left(f, P_{m}\right)-\int_{a}^{c} f\right|+\left|S\left(f, P_{k}\right)-\int_{c}^{b} f\right| \\
& <\frac{\varepsilon}{2}+\frac{\varepsilon}{2}=\varepsilon .
\end{aligned}
$$

Sehingga, terbukti bahwa $f \in H^{*}([a, b])$ dan $\int_{a}^{b} f=\int_{a}^{c} f+\int_{c}^{b} f$.

Berikut akan diberikan sifat yang menyatakan bahwa Apabila suatu fungsi terintegral Henstock pada suatu interval, maka fungsi tersebut juga terintegral Henstock Sekuensial pada setiap subintervalnya.

Teorema 3.6. (Paxton, 2016:19) Diberikan $f: I \subseteq \mathbb{R} \rightarrow \mathbb{R}$. Jika $f \in H^{*}(I)$, maka $f \in H^{*}\left(I_{i}\right)$ dengan $i=1,2,3, \ldots k \in \mathbb{N}$

\section{Bukti:}

Akan dibuktikan bahwa $f \in H^{*}\left(I_{i}\right)$ artinya fungsi $f$ terintegral Henstock Sekuensial pada setiap subinterval $I_{i}, \forall i=1,2,3, \ldots k \in \mathbb{N}$ dengan menggunakan induksi matematika.

Pertama, akan dibuktikan benar untuk $k=2$. Diberikan $\varepsilon>0$, maka terdapat $\delta_{N}(x) \in\left\{\delta_{n}(x)\right\}_{n=1}^{\infty}$ sehingga untuk setiap $n \geq N$ dan $P_{n}=\left\{\left(I_{i}, t_{i}\right)\right\}_{i=1}^{k}$ yang merupakan partisi $\delta_{n}(x)$ - fine pada $I$, berlaku

$$
\left|S\left(f, P_{n}\right)-\int_{I} f\right|<\frac{\varepsilon}{2} .
$$

Selanjutnya, diberikan interval $I_{1}$ dan $I_{2}$ dengan $I_{1} \cap I_{2} \neq \varnothing$ dan $I_{1} \cup I_{2}=I$. Diberikan pula $\delta_{1 n}(x)$ dan $\delta_{2 n}(x)$ berturut-turut merupakan gauge pada $I_{1}$ dan $I_{2}$, sehingga untuk sebarang $P_{1 n}$ yang merupakan partisi $\delta_{1 n}(x)$ - fine dan $P_{2 n}$ yang merupakan partisi $\delta_{2 n}(x)-$ fine berlaku

$$
\begin{aligned}
S\left(f, P_{n}\right) & =\sum_{i=1}^{2} f\left(t_{i}\right)\left(x_{i}-x_{i-1}\right)_{n} \\
& =f\left(t_{1}\right)\left(x_{1}-x_{0}\right)_{n}+f\left(t_{2}\right)\left(x_{2}-x_{1}\right)_{n} \\
& =S\left(f, P_{1 n}\right)+S\left(f, P_{2 n}\right) .
\end{aligned}
$$


Perhatikan bahwa jika $Q_{16}$ merupakan partisi $\delta_{1 n}(x)$ - fine dan $P_{2 n}$ merupakan partisi $\delta_{2 n}(x)-$ fine maka $R_{n}=Q_{1 n} \cup P_{2 n}$ merupakan partisi $\delta_{n}(x)$ - fine, untuk setiap $n=1,2,3 \ldots$ Selanjutnya diberikan $\varepsilon>0$, maka terdapat $\delta_{N}(x) \in\left\{\delta_{n}(x)\right\}_{n=1}^{\infty}$ sehingga untuk setiap $n \geq N$ dan $P_{1 n}, Q_{1 n}$ merupakan partisi $\delta_{1 n}(x)$ - fine pada $I$, berlaku

$$
\begin{aligned}
& \left|S\left(f, P_{1 n}\right)-S\left(f, Q_{1 n}\right)\right| \\
& =\left|S\left(f, P_{1 n}\right)-S\left(f, Q_{1 n}\right)+S\left(f, P_{2 n}\right)-S\left(f, P_{2 n}\right)+\int_{I} f-\int_{I} f\right| \\
& \leq\left|S\left(f, P_{1 n}\right)+S\left(f, P_{2 n}\right)-\int_{I} f\right|+\left|S\left(f, Q_{1 n}\right)+S\left(f, P_{2 n}\right)-\int_{I} f\right| \\
& =\left|S\left(f, P_{n}\right)-\int_{I} f\right|+\left|S\left(f, R_{n}\right) \int_{I} f\right| \\
& \leq \frac{\varepsilon}{2}+\frac{\varepsilon}{2}=\varepsilon .
\end{aligned}
$$

Selanjutnya, diasumsikan benar untuk $k=l$, sehingga akan dibuktikan benar untuk $k=l+1$. Diberikan sebarang $\varepsilon>0$, maka terdapat $\delta_{N}(x) \in\left\{\delta_{n}(x)\right\}_{n=1}^{\infty}$ sehingga untuk setiap $n \geq N$ dan $P_{(l+1)_{n}}, Q_{(l+1)_{n}}$ yang merupakan partisi $\delta_{(l+1)_{n}}$ - fine pada $I_{(l+1)}$, berlaku

$$
\begin{aligned}
& \left|S\left(f, P_{(l+1)_{n}}\right)-S\left(f, Q_{(l+1)_{n}}\right)\right| \\
& \leq \mid S\left(f, P_{(l+1)_{n}}\right)+\left[S\left(f, P_{1 n}\right)+S\left(f, P_{2 n}\right)+\cdots+S\left(f, P_{l n}\right]-\int_{I} f \mid\right. \\
& \quad+\mid S\left(f, Q_{(l+1) n}+\left[S\left(f, P_{1 n}\right)+S\left(f, P_{2 n}\right)+\cdots+S\left(f, P_{l n}\right)\right]-\int_{I} f \mid\right. \\
& =\left|S\left(f, P_{n}\right)-\int_{I} f\right|+\left|S\left(f, R_{n}\right) \int_{I} f\right| \\
& \leq \frac{\varepsilon}{2}+\frac{\varepsilon}{2}=\varepsilon,
\end{aligned}
$$

sehingga terbukti bahwa fungsi $f \in H^{*}\left(I_{i}\right)$ dengani $=1,2,3, \ldots k \in \mathbb{N}$.

\section{Kesimpulan}

Pendefinisian Integral Henstock Sekuensial hampir sama seperti mendefinisikan integral Henstock, bedanya pada integral Henstock Sekuensial partisinya melibatkan barisan fungsi positif yang disebut partisi tag $\delta$-fine. Sifat-sifat yang berlaku pada integral Henstock berlaku pula pada integral Henstock Sekuensial, beberapa diantaranya berikut ini. Apabila suatu fungsi terintegral Henstock Sekuensial pada dua subinterval tertutup yang dimuat oleh suatu interval tertutup, maka fungsi tersebut juga terintegral Henstock Sekuensial pada interval tertutup tersebut, dan nilai integral dari fungsi yang terintegral Henstock Sekuensial pada interval tertutup tersebut merupakan penjumlahan dari nilai integral fungsi yang terintegral Henstock Sekuensial pada dua subinterval tersebut. Selanjutnya apabila suatu fungsi terintegral Henstock pada suatu interval, maka fungsi tersebut juga terintegral Henstock Sekuensial pada setiap subintervalnya. Selain itu, apabila diberikan fungsi non negative maka nilai integral Henstock Sekuensial dari fungsi tersebut juga bernilai non negative. Sifat lainnya mengatakan bahwa nilai integral Henstock Sekuensial dari perkalian scalar dan suatu fungsi sama dengan scalar tersebut dikalikan dengan nilai dari integral Henstock sekuensial fungsi tersebut. 


\section{Referensi}

[1] Bartle Robert G., 2000, Intrduction to Real Analysis, Third Edition, John Wiley and Sons, Inc, USA.

[2] Bartle Robert G., 2000, A Modern Theory of Integration, Graduate Studies in Mathematics, Vol. 32. American Mathematical Society, Providence, RI.

[3] Lee Tuo Yeong, 2006, Multipliers for Generalized Riemann Integrals in the Real Line, Mathematica Bohemica, Singapore

[4] Lee Tuo Yeong, 2011, Henstock-Kurzweil Integration on Euclidean Spaces, Series in Real Analysis, Vol.12, World Scientific.

[5] Paxton Laramie, 2016, A Sequential Approach to the Henstock Integral, Washington State University.

[6] Wells Jonathan, 2011, Generalizations of the Riemann Integral:An Investigation of the Henstock Integral, diakses tanggal 16 Agustus 2017. https://www.whitman.edu/Documents/Academics/Mathematics/SeniorProject_JonathanWells.pdf 